\title{
Accumulation of polyphosphate granules in Helicobacter pylori cells under anaerobic conditions
}

\author{
MUTSUNORI SHIRAI, JUNKO KAKADA, KAZUO SHIBATA*, MUHAMMAD G. MORSHED, \\ TADAHIRO MATSUSHITA* and TERUKO NAKAZAWA
}

Department of Microbiology, Yamaguchi University School of Medicine, Minami-Kogushi 1-1-1, Ube City, Yamaguchi 755-8505 and *Pharmaceutical Development Research Laboratory, Tanabe Seiyaku, 2-2-50 Kawagishi, Toda, Saitama 335-0015, Japan

\begin{abstract}
Helicobacter pylori is known to transform to coccoid forms which might be involved in faecal-oral transmission. When the bacteria enter the intestine, they encounter anaerobiosis that is unfavourable for growth. The effect of anaerobiosis was investigated to determine whether $H$. pylori is viable under such conditions. $H$. pylori in the late logarithmic growth phase transformed from spiral to coccoid forms when transferred to and incubated anaerobically in fresh medium. Acridine orange staining indicated that the viability of coccoid forms was significantly reduced, but still measurable even at day 5 or 7 of anaerobic culture. The cells retained low but significant levels of the major sigma factor RpoD at day 5 or 7 of anaerobic culture. The cellular structures of coccoid forms contained polyphosphate granules at day 1 and even at day 7 when incubated anaerobically, whereas only a few granules were observed under micro-aerobic conditions. Poor formation of polyphosphate granules in micro-aerobic cultures correlated particularly well with lower levels of acridine orange staining. These results suggest that acridine orange-positive anaerobic coccoid forms are viable to a certain extent and that polyphosphate may support this viability.
\end{abstract}

\section{Introduction}

Helicobacter pylori, a gram-negative spiral bacterium first isolated in 1982 from a patient with chronic active gastritis [1], is responsible for a large proportion of chronic gastritis, nearly all duodenal ulcers, most gastric ulcers and probably an increased risk of gastric adenocarcinoma $[2,3]$. More than $50 \%$ of the adult population is infected with $H$. pylori in developing as well as in developed countries [4].

The micro-organisms exist in two forms, an actively dividing spiral form and a coccoid form (a form of growth arrest) that is observed under various stress conditions, including starvation of nutrients $[5,6]$. There is controversy as to whether the coccoid forms of H. pylori and Campylobacter jejuni are degenerative with no risk of infection or just a stage which is dormant but viable [7-9]. The coccoid form has been

Received 25 May 1999; revised version accepted 6 Oct. 1999.

Corresponding author: Dr T. Nakazawa (e-mail: nakazawa@ po.cc.yamaguchi-u.ac.jp). suspected to play a role in the transmission of the bacteria and may be partly responsible for the recrudescence or relapse of infection after antimicrobial treatments $[7,10,11]$. Although the mode of transmission still remains unclear, oral-oral and faecal-oral routes of transmission have been suggested [12]. If $H$. pylori follows the latter route, organisms must pass through the anaerobic atmosphere of the alimentary tract, which is an unfavourable environment for H. pylori.

The basic metabolism and energy supply during the coccoid conversion of $H$. pylori remain unclear. It has been suggested that some of the cocci can revert back to spiral morphology and re-grow $[12,13]$. Polyphosphate granules represent energy and phosphorus sources, and may supply an alternative energy source when ATP is insufficient $[14,15]$. Polyphosphate granules have been found in the coccoid forms of $H$. pylori [16]. The polyphosphates may constitute an accessible energy source for survival of the dormant coccoid form and may permit it to re-grow, once an appropriate environment is encountered. In this study, the properties of cells that survived for a prolonged 
incubation period in the stationary phase under microaerobic or anaerobic conditions were studied by ultrastructural and functional analysis.

\section{Materials and methods}

\section{Culture and staining of bacteria}

H. pylori strain HPK5 derived from a gastric ulcer patient was cultivated at $37^{\circ} \mathrm{C}$ for $48 \mathrm{~h}$ in Brucella Broth (Difco Laboratories, Detroit, MI, USA) containing heat-inactivated horse serum 5\% (brucella-serum broth) in a micro-aerobic atomosphere $\left(\mathrm{O}_{2} 5 \%, \mathrm{CO}_{2}\right.$ $\left.15 \%, \mathrm{~N}_{2} 80 \%\right)$ with shaking [17]. The dense culture $\left(\mathrm{OD}_{590} 1.2\right)(25 \mathrm{ml})$ was harvested by centrifugation, resuspended in $12.5 \mathrm{ml}$ of fresh brucella broth containing heat-inactivated horse serum $1 \%$ or $5 \%$, and split into two portions that were either introduced in to an anaerobic chamber with the BBL gas-pack anaerobic system (Becton Dickinson, Cockeysville, USA) or further incubated under micro-aerobic conditions until day 7. The gas-pack system was used instead of an oxygen-free gas mixture to produce strictly anaerobic conditions. Samples for immunoblotting and electron microscopy were obtained periodically from cultures grown in brucella-serum broth. The total number of bacteria was determined with a counting chamber. The number of cfu was determined by spreading $100 \mu \mathrm{l}$ of 10-fold serial dilutions on Brucella Agar (Difco Laboratories) supplemented with heat-inactivated horse serum 5\% (brucella-serum agar) and incubated microaerobically for 3 days (minimal detection level, $100 \mathrm{cfu} / \mathrm{ml}$ ). Acridine orange staining was done by conventional methods [18]. Briefly, cells were fixed with methanol for $2 \mathrm{~min}$, stained with acridine orange (Difco) $0.01 \% \mathrm{w} / \mathrm{v}$ for $2 \mathrm{~min}$, rinsed thoroughly with distilled water and observed with a fluorescent microscope. Then c. 500-1000 orange fluorescent cells were counted to measure the number of acridine orangepositive cells/5 or $10 \mu \mathrm{l}$ of 10 -fold serial dilutions of the culture at each time point to give the cell number $/ \mathrm{ml}$. The percentage of acridine orange-positive cells was calculated as $100 \times[$ (number of acridine orange positive cells $/ \mathrm{ml}$ at each time point)/(number of acridine orange positive cells $/ \mathrm{ml}$ at day 0$)]$. After Gram's staining, c. 200 cells were counted to measure the proportion of coccoid forms (morphologically round or horse-shoe form).

\section{Immunoblotting}

The intracellular level of the rpoD gene product was determined by using cell lysate preparations as reported previously [19]. Briefly, cells were harvested by centrifugation $(2000 \mathrm{~g}$ for $10 \mathrm{~min}$ ), washed twice with glycerol $10 \%$ and resuspended in $40 \mathrm{mM}$ Tris- $\mathrm{HCl}(\mathrm{pH}$ 8.1 at $4^{\circ} \mathrm{C}$ ) containing sucrose $25 \%$. After treatment with $1 \mathrm{mM}$ EDTA and lysozyme $500 \mu \mathrm{g} / \mathrm{ml}$ at $4^{\circ} \mathrm{C}$ for $10 \mathrm{~min}$, cells were lysed by adding Brij58 (Aldrich Chemical Co., Milwaukee, USA) $0.5 \%$. The Brij58 lysate was supplemented with $0.01 \mathrm{M} \mathrm{MgCl}_{2}$ and $0.2 \mathrm{M} \mathrm{KCl}$, digested at $37^{\circ} \mathrm{C}$ for $10 \mathrm{~min}$ with RNAase A $20 \mu \mathrm{g} / \mathrm{ml}$ and DNAase I $100 \mu \mathrm{g} / \mathrm{ml}$ in the presence of $1 \mathrm{mM}$ phenylmethylsulphonyl fluoride (PMSF) and sonicated for $1 \mathrm{~min}$. The supernate obtained after centrifugation for $30 \mathrm{~min}$ at $15000 \mathrm{rpm}$ was used as the cell lysate for all the experiments. The protein concentration of cell lysate was determined with a protein assay kit (BioRad, Hercules, USA). Samples containing $10 \mu \mathrm{g}$ of total protein were applied to SDSpolyacrylamide $10 \%$ gel. After electorophoresis, protein bands were electrotransferred to polyvinylidene difluoride membranes (Millipore, Bedford, USA) and probed with monospecific rabbit antibody raised against the purified Escherichia coli RNA polymerase sigma 70 subunit (a gift from Dr Ishihama, National Institute of Genetics, Mishima, Japan) and detected by the enhanced chemiluminescence reagent system (Amersham Pharmacia Biotech, Uppsala, Sweden).

\section{Electron microscopy}

Bacteria were harvested from the culture, fixed in glutaraldehyde $2.5 \%$, washed and post-fixed in osmium tetroxide. After post-fixation, the materials were dehydrated and embedded in epoxy medium. The grids with thin sections were contrasted with $2 \%$ uranyl acetate and lead citrate and examined with an electron microscope. For scanning electron microscopy (SEM), after the samples were fixed with glutaraldehyde $2.5 \%$ and osmium tetroxide $1 \%$, they were dehydrated with a graded series of ethanol and replaced with isoamyl acetate, followed by critical point drying and coating with platinum. The cells were observed with a Hitachi high resolution scanning electron microscope S-4200 (Hitachi, Tokyo, Japan).

\section{Results}

\section{Characteristics of $H$. pylori coccoids in micro- aerobic and anaerobic cultures}

When the cells of $H$. pylori HPK5 were incubated at a concentration of $2.8 \times 10^{8}$ cells $/ \mathrm{ml}$ in fresh brucellabased medium under anaerobic or micro-aerobic conditions, the proportion of the coccoid form of $H$. pylori HPK5 increased from 0 (day 0) to $100 \%$ (day 5) while the number of cfu decreased (Fig. 1a and b). A steady decline in viable count was seen; by day 5 the count was appreciably lower under micro-aerobic conditions. On day 7 under anaerobic conditions with $5 \%$ serum a small fraction of the original culture $(c$. $0.01 \%$ ) survived, whereas under micro-aerobic conditions the culture seemed sterile. The count under anaerobic conditions with $1 \%$ serum was about tenfold lower than that with $5 \%$ serum.

Microscopic examination of gram-stained films revealed that organisms in the stationary phase culture of H. pylori HPK5 changed their morphology from the 
a

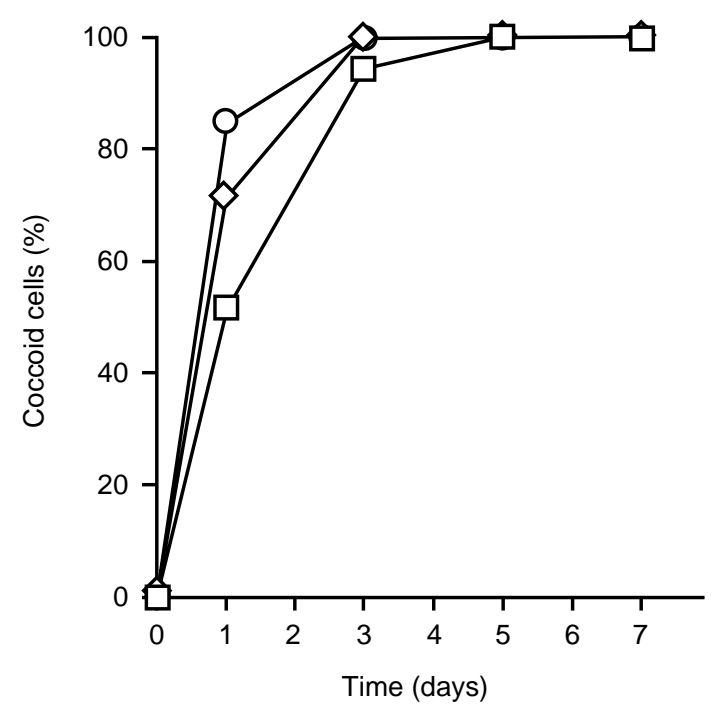

C

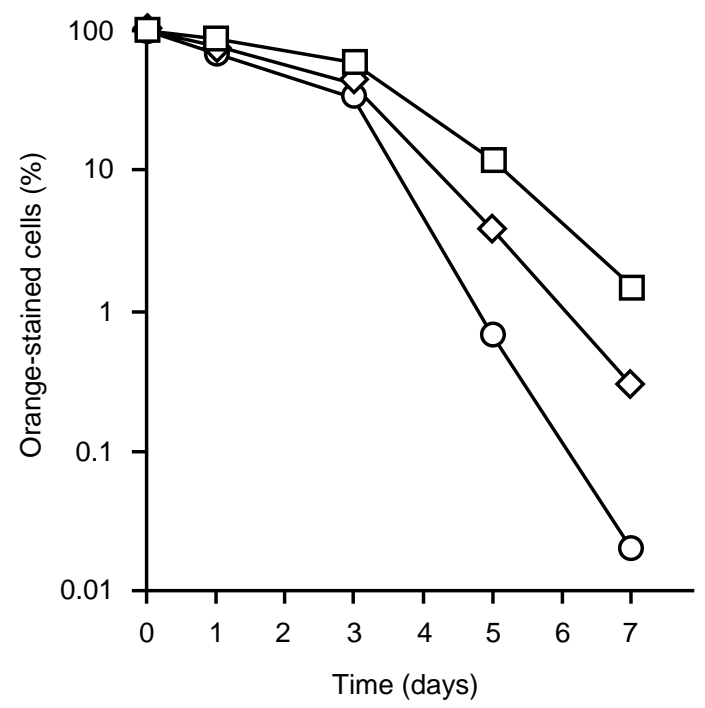

spiral to the coccoid form markedly under the anaerobic conditions (not shown). Almost all the cells changed to the coccoid form after anaerobic incubation for 3 days and $1.3 \times 10^{5}$ cells (c. $0.1 \%$ ) produced colonies on brucella agar at day 5 (Fig. $1 \mathrm{a}$ and $\mathrm{b}$ ). To distinguish between live and dead cells, methanol-fixed samples were stained with acridine orange. Once stained, the cells should fluoresce orange if alive and green if non-viable. Many coccoid cells of strain HPK5 fluoresced orange (not shown). The number of acridine orange-stained coccoid organisms decreased with increasing length of incubation, but some still remained even after incubation for 5 days (Fig. 1c). After incubation for several days, most of the cells had lost culturability when assayed for cfu, but they fluoresced orange (non-culturable but alive) (Fig. $1 \mathrm{~b}$ and $\mathrm{c}$ ). The number of acridine orange-stained cells significantly decreased under the micro-aerobic conditions, while there was an intermediate reduction under anaerobic conditions with $1 \%$ serum (Fig. 1c). Conversely, the $\mathrm{b}$

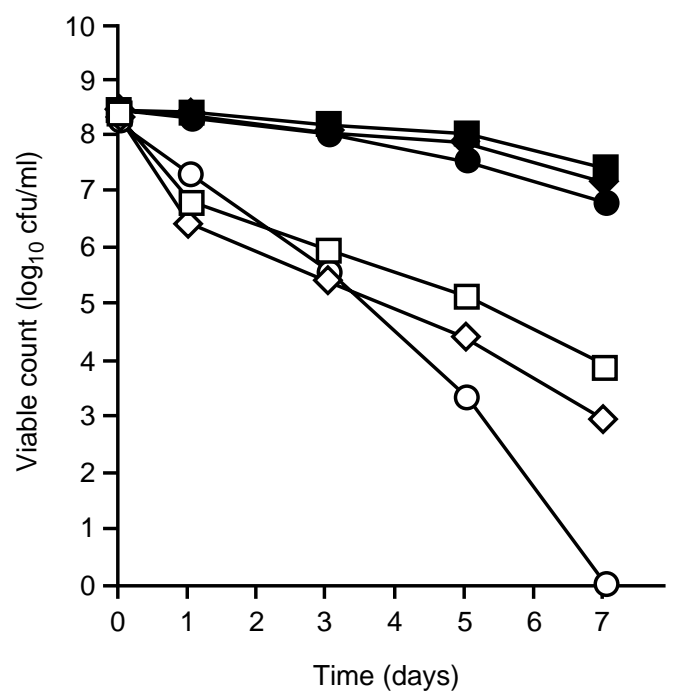

Fig. 1. Viability and morphology of H. pylori HPK5 cells maintained in fresh brucella-based media under anaerobic or micro-aerobic conditions. (a) Percentages of coccoid forms in total number of bacteria determined by Gram's staining; (b) cfu (open symbols) and total numbers of bacteria (closed symbols) (the values are the mean of triplicate counts, SE $<10 \%$ of the mean); (c) percentages of acridine orange-stained cells (the percentage of fluorescing orange cells was calculated as described in Materials and methods). The results shown are representative of three repeat experiments, which all gave similar results. Anaerobic incubation with serum $5 \%(\square)$, anaerobic incubation with serum $1 \%(\diamond)$, micro-aerobic incubation with $5 \%$ serum $(O)$.

acridine orange-stained cells remained viable at a high rate under anaerobic conditions with $5 \%$ serum. It is possible that the colonies came from the acridine orange-stained coccoid bodies which remained viable under the anaerobic conditions, although the possibility cannot be ruled out that they came from a few residual spiral bacteria.

\section{Intracellular levels of RpoD in the coccoid form of $H$. pylori}

In $E$. coli, it is well known that resistance to stress is controlled by sigma factors such as RpoH and RpoS, in addition to RpoD, the principal sigma factor [20, 21]. As $H$. pylori has only RpoD among these sigma factors [22], the intracellular level of the $r p o D$ gene product must be important for bacteria to survive under adverse circumstances, and thus the intracellular level of RpoD protein should reflect the activity or viability of the bacterial cells. 
The intracellular level of RpoD in H. pylori HPK5 was determined with a polyclonal anti- $E$. coli $\sigma 70$ antibody that recognised the $H$. pylori RpoD cross-reactively. RpoD protein was maintained at a constant level throughout the logarithmic growth phase (not shown), but the levels were significantly reduced at day 1 and further reduced at day 3 after the start of incubation. The levels were relatively higher under the anaerobic conditions than those under the micro-aerobic conditions at day 3 and 7 (Fig. 2).

\section{Ultrastructure of $H$. pylori in micro-aerobic and anaerobic cultures}

The ultra-thin sections of strain HPK5 showed that accumulation of polyphosphate granules [16], predominantly in the cytoplasm, increased on days 1,3 and 7 of incubation under anaerobic conditions (Fig. 3a). However, under micro-aerobic conditions, granule formation was poor - especially on days 3 and 7 (Fig. 3b). In addition, sections of cells taken from cultures incubated in micro-aerobic conditions on day 7 showed degenerative structural components such as cell walls, cell membranes and cytoplasm, whereas the 7day-old anaerobic coccoid forms still preserved the cellular structures, which probably require maintenance of a certain level of metabolism. Separation between the cytoplasmic and chromatinic contents and the parietal structures of the bacterial cells was also prominent in the micro-aerobically cultured bacteria (Fig. 3b). Polar membranes, reported previously [23], were also maintained in several intact coccoid organisms produced under anaerobic conditions (not shown). Scanning electron microscopy showed that the coccoid structures were well-conserved at day 7 of anaerobic culture, whereas most cells of the micro-aerobic culture showed deformation or collapse of the coccoid structures and formed large aggregates at day 7 (Fig. 3c).

The formation of polyphosphate on days $0,1,3$ and 7 of the bacterial culture under micro-aerobic or

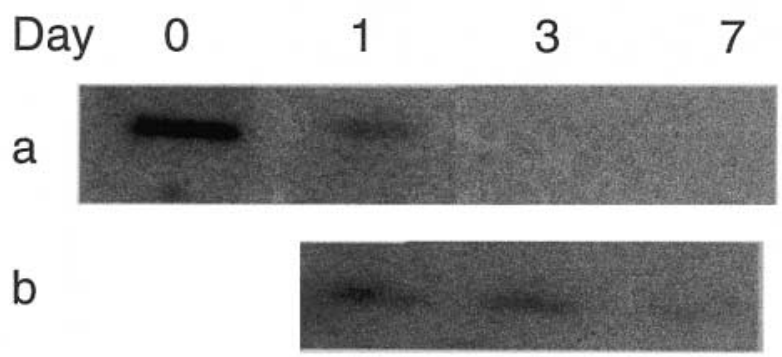

Fig. 2. Immunoblot analysis of the major sigma factor of H. pylori HPK5. The quantity of RpoD protein of the cells maintained in different growth phases under (a) micro-aerobic conditions or (b) anaerobic conditions was analysed. Strain HPK5 cells were grown in brucellaserum $5 \%$ broth and harvested on days $0,1,3$ and 7 , respectively, and lysate samples containing $10 \mu \mathrm{g}$ of protein were applied. The lower detection limit of the immunoblot was $0.2 \mu \mathrm{g}$ of protein corresponding to $c$. $4 \times 10^{4}$ viable cells at day 0 . anaerobic atmosphere were assessed by electron microscopy. Polyphosphate formation by the bacteria was significantly lower under micro-aerobic conditions than under anaerobic conditions at the equivalent time points (Fig. 4).

\section{Discussion}

In recent years, the expression 'viable but nonculturable' has been applied to cells with various physiological attributes that include apparent cell integrity, the possession of some form of measurable cellular activity and the apparent capacity to regain culturability. However, most of the reports claiming a return to culturability have failed to exclude the regrowth of a limited number of cells which have never lost culturability [24]. The population examined in the present study were probably uninjured cells that retain activity yet fail to grow on the standard media for the experiments without going through a resuscitation process as defined by Kell et al. [24]. The transition process from non-culturability to culturability should be energy-dependent. The present study investigated the effect of a high density of bacterial population in a fresh medium on its tolerance against the deleterious conditions created under micro-aerobic and anaerobic conditions.

The numbers of cfus observed under micro-aerobic conditions were higher than those under anaerobic conditions on day 1 , but the reverse was true after day 5. Donelli et al. [25] reported an apparently contradictory observation that the cfu number and coccoid formation of $H$. pylori were lower under anaerobic conditions than under micro-aerobic conditions. The major difference in the experimental conditions was that they started to grow the bacteria at a very early growth phase (100-fold dilution of cultured bacteria), whereas the present study maintained the two-fold concentrated bacteria from a dense culture in a nutrient-rich fresh medium. It appears that the bacteria require micro-aerobic conditions for proliferation, but seem to prefer anaerobic conditions for survival.

Little is known about the basic metabolism of $H$. pylori and how this organism gains energy during the coccoid conversion. Polyphosphate granules represent a reservoir for stored energy and phosphorus, and may be a reservoir for an alternative energy source when ATP is insufficient [14]. Mutants that fail to express $p p k$, the gene that encodes the polyphosphate kinase (PPK) responsible for the synthesis of polyphosphate in $E$. coli, fail to develop the resistance to heat, oxidants and osmotic stresses characteristic of stationary-phase cells and lose their viability within a few days [14]. Recently the gene for PPK was assigned in H. pylori [22]. The gene is thought to regulate various distinct metabolic processes of $H$. pylori, because the productivity of ATP seems to be not so high in $H$. pylori on the basis of 
a

Day 0

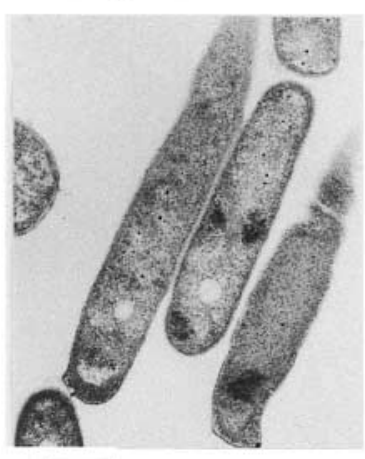

b
Day 3
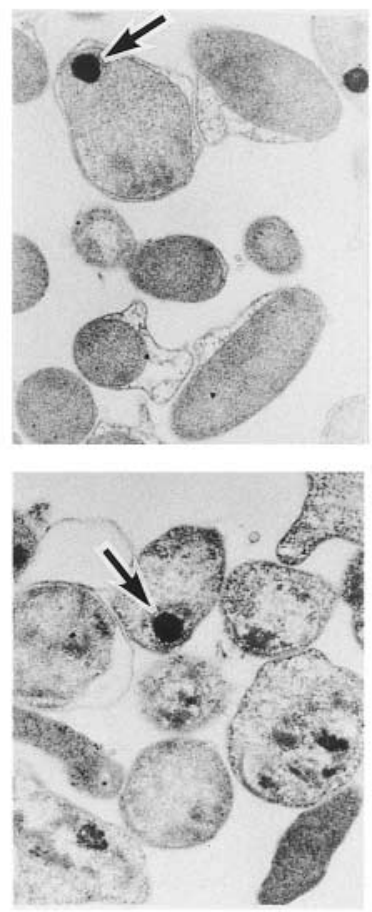

Day 7
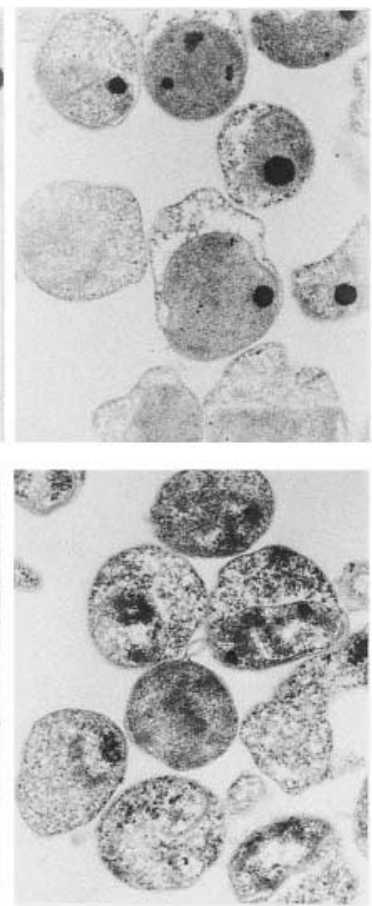
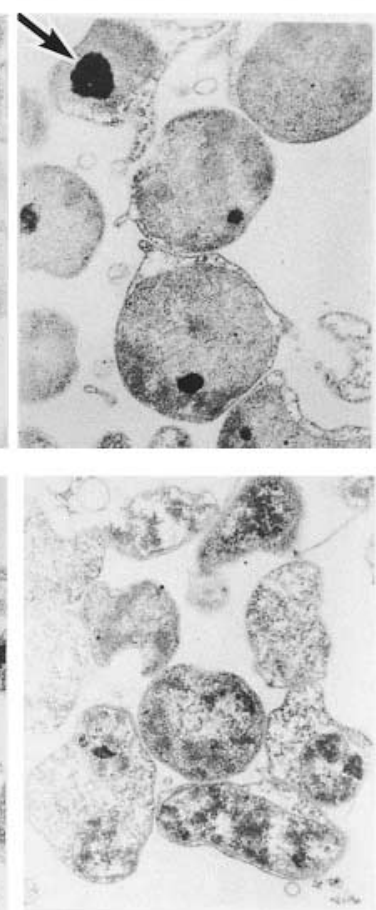

C Day 0

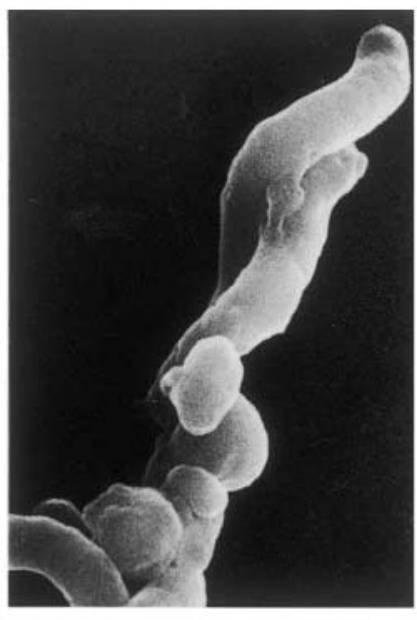
Day 7 (Anaerobic)

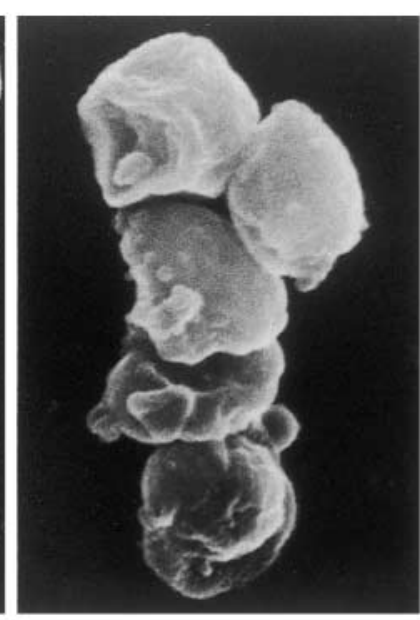

Day 7 (Microaerobic)

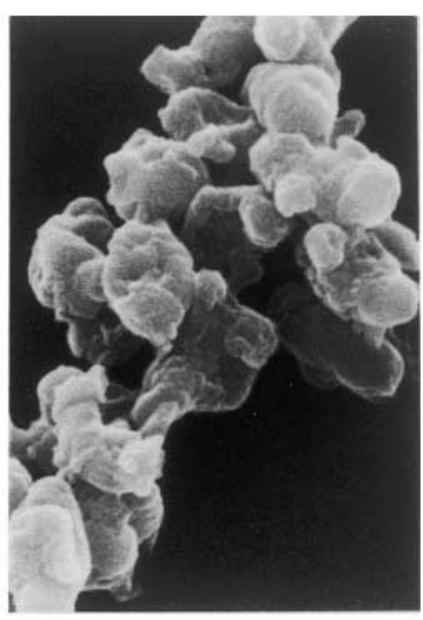

Fig. 3. Ultrastructure of the coccoid form. Ultra-thin sections $(\times 20000)$ of a culture of $H$. pylori HPK5 were taken for electron microscopy on days $0,1,3$ and 7 . The bacteria were maintained in brucella-serum $5 \%$ broth under (a) anaerobic or (b) micro-aerobic conditions. (c) Scanning electron microscopic views $(\times 16500)$. Arrows indicate polyphosphate granules (a and b). Bar, $500 \mathrm{~nm}$.

metabolic maps [22]. The results of the present study have for the first time characterised the polyphosphate structures in association with the coccoid form cultured under anaerobic conditions.

It is considered that nucleic acid synthesis in an exponential growth phase inhibits polyphosphate deposition and stimulates its degradation, so that no significant polyphosphate accumulation can occur $[15,26]$. This means that growth arrest in the presence of rich nutrients under the anaerobic conditions in the present study promotes polyphosphate deposition in the bacterium. The presence of polyphosphate granules with the preserved cell structures under the anaerobic conditions rather than under the micro-aerobic conditions seems to confirm their supposed role in energy metabolism of the micro-organism. Separation between the cytoplasmic contents and the parietal structures, which was often observed in the micro-aerobic coccoid forms, may represent the morphological manifestation of bacterial cell damage in the metabolism. The presence of polyphosphates as energy and phosphorus 


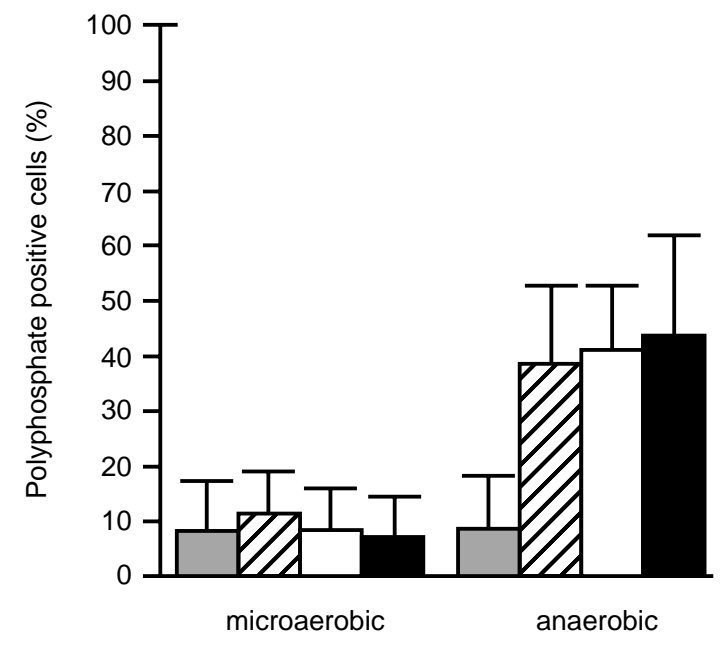

Culture conditions

Fig. 4. The formation of polyphosphate on days 0 ( $\square$ ), 1 $(\mathbb{E}), 3(\square)$ and 7 (ם) of the bacterial culture maintained under micro-aerobic or anaerobic atmosphere during the transformation from helical form to coccoid form. The percentages of bacteria carrying cytoplasmic polyphosphate granules $>0.1 \mu \mathrm{m}$ in diameter out of 200 bacterial cells in random fields were determined by electron microscopic observation $(\times 2000, \times 5000, \times 10000)$. The polyphosphate formation of the bacterium (\%) was significantly reduced under micro-aerobic conditions as compared with anaerobic conditions on the same day ( $\mathrm{p}<0.05$ by Student's $t$ test). Data $(\%)$ are expressed as mean and $\mathrm{SD}(\mathrm{n}=4)$.

sources may permit a certain level of endogenous metabolism to preserve RNA and DNA, as well as structural components like the cell wall, cell membrane and cytoplasm for a long period. Polyphosphates may permit $H$. pylori to maintain its viability under various stresses and thus constitute an accessible reserve for synthesis of the metabolic intermediates which may facilitate survival of the coccoid forms.

It is possible that polyphosphate granules play some role in the maintenance of metabolism and structures under anaerobic conditions. Therefore, the above results suggest the possibility that $H$. pylori could pass through the adverse conditions of the anaerobic route through the human alimentary tract by changing its morphology. The results also predict that, although nearly $100 \%$ of the cells changed to the coccoid form under the anaerobic conditions, some of them fulfilled the criteria for viability as judged by acridine orange staining and expression of RpoD after a long period of exposure to the anaerobic atmosphere. It is tempting to speculate that polyphosphate may support the acridine orange signals and expression of RpoD. However, the capacity for the acridine orange positive cells to regain culturability or retain infectivity, or both, is undetermined as yet.

A previous study reported that coccoid $H$. pylori not culturable in vitro reverted in mice [12]. It appears that once the dormant coccoid form finds an appropriate environment, it colonises the host after reversion. This dormant coccoid form should represent a natural phenomenon or an alternative system of survival. The results of the present study indicate that preferential requirements for survival of coccoid forms are anaerobiosis and a rich source of nutrients. The coccoid forms, which were cultured under microaerobic conditions with a poor supply of nutrients, may represent the growing cells of $H$. pylori in gastric mucosal erosion, whereas those cultured in anaerobic conditions with a rich supply of nutrients may represent the bacterium with growth arrest in the intestine. The results emphasise that polyphosphate-positive coccoid cells may be involved in faecal-oral transmission. Efforts to re-grow $H$. pylori from the stool samples of H. pylori-infected mice have not succeeded to date, but most of the samples were positive for $H$. pylori by PCR (unpublished results). It has been found that $H$. pylori transmitted very frequently from the infected mice to the non-infected mice kept in the same chamber (unpublished results). The number of $\mathrm{cfu}$ obtained with a 7-day anaerobic culture was higher than that observed with the same strain after microaerobic culture. The coccoid forms are likely to be viable in terms of the positivity of acridine orange staining for mRNA under anaerobic conditions. A recent report suggested that the amount of nucleic acids was significantly reduced in the coccoid form of H. pylori and the coccoid form is a morphological manifestation of bacterial cell death [27]. On the other hand, it has been suggested that some of the cocci can revert to the spiral morphology with a full recovery of urease activity [13].

It was not possible to show directly whether coccoid forms are capable of re-growth, but the present study showed several lines of evidence that anaerobic incubation at high density retards degeneration of the cells compared with micro-aerobic incubation. However, the possibilities that the accumulation of polyphosphate represents an enzyme imbalance under anaerobic conditions, and that the occurrence of larger phosphate granules in some coccoid cells simply reflects the combination of changes in morphology and retention of membrane integrity in slowly degenerating population cannot be excluded. The morphological characterisation of $H$. pylori cultivated for long periods of time gives insights into its unique life cycle. Further analysis of the coccoid form and its regulation in $H$. pylori will also provide the basis for understanding the pathogenesis and developing effective strategies for the treatment or prevention of gastroduodenal ulcer and gastric cancer in patients infected with this bacterium.

We are grateful to A. Ishihama for the gift of antibodies. This work was supported in part by a grant-in-aid from the Ministry of Education, Science and Culture of Japan (06670560, 08670347, 08457089) and Suzuki Kentarou Memorial Foundation Award 1997. 


\section{References}

1. Marshall BJ, Warren JR. Unidentified curved bacilli in the stomach of patients with gastritis and peptic ulceration. Lancet 1984; 1: 1311-1315.

2. Parsonnet J, Hansen S, Rodriguez L et al. Helicobacter pylori infection and gastric lymphoma. $N$ Engl J Med 1994; 330: 1267-1271.

3. NIH Consensus Development Panel on Helicobacter pylori in peptic ulcer disease. Helicobacter pylori in peptic ulcer disease. JAMA 1994; 272: 65-69.

4. Mégraud F. Epidemiology of Helicobacter pylori infection. Gastroenterol Clin North Am 1993; 22: 73-88.

5. Jones DM, Sutcliffe EM, Curry A. Recovery of viable but nonculturable Campylobacter jejuni. J Gen Microbiol 1991; 137: 2477-2482.

6. Lai-King NG, Sherburne R, Taylor DE, Styles ME. Morphological forms and viability of Campylobacter species studied by electron microscopy. J Bacteriol 1985; 164; 338-343.

7. Bode G, Mauch F, Malfertheiner P. The coccoid forms of Helicobacter pylori. Criteria for their viability. Epidemiol Infect 1993; 111: 483-490.

8. Buck GE, Parshall KA, Davis CP. Electron microscopy of the coccoid form of Campylobacter jejuni. J Clin Microbiol 1983; 18: $420-421$.

9. Moran AP, Upton ME. Factors affecting production of coccoid forms by Campylobacter jejuni on solid media during incubation. J Appl Bacteriol 1987; 62: 527-537.

10. Catrenich CE, Makin KM. Characterization of the morphologic conversion of Helicobacter pylori from bacillary to coccoid forms. Scand J Gastroenterol 1991; 26 Suppl 181: 58-64.

11. Mai U, Geis G, Leying H, Rühl G, Opferkuch W. Dimorphism of Campylobacter pylori. In: Mégraud F, Lamouliatte H (eds) Gastroduodenal pathology and Campylobacter pylori. (Excerpta Medica International Congress Series no. 847) Amsterdam, Elsevier Science Publishers. 1989: 29-33.

12. Cellini L, Allocati N, Angelucci D et al. Coccoid Helicobacter pylori not culturable in vitro revert in mice. Microbiol Immunol 1994; 38: 843-850.

13. Andersen AP, Elliott DA, Lawson M, Barland P, Hatcher VB, Puszkin EG. Growth and morphological transformations of Helicobacter pylori in broth media. J Clin Microbiol 1997; 35 : 2918-2922.

14. Rao NN, Kornberg A. Inorganic polyphosphate supports resistance and survival of stationary-phase Escherichia coli. $J$ Bacteriol 1996; 178: 1394-1400.
15. Rao NN, Roberts MF, Torriani A. Amount and chain length of polyphosphates in Escherichia coli depend on cell growth conditions. J Bacteriol 1985; 162: 242-247.

16. Bode G, Mauch F, Ditschuneit H, Malfertheiner P. Identification of structures containing polyphosphate in Helicobacter pylori. J Gen Microbiol 1993; 139: 3029-3033.

17. Tsuda M, Karita M, Morshed MG, Okita K, Nakazawa T. A urease-negative mutant of Helicobacter pylori constructed by allelic exchange mutagenesis lacks the ability to colonize the nude mouse stomach. Infect Immun 1994; 62: z3586-3589.

18. Zambrano MM, Siegele DA, Almiron M, Tormo A, Kolter R. Microbial competition: Escherichia coli mutants that take over stationary phase cultures. Science 1993; 259: 1757-1760.

19. Jishage M, Iwata A, Ueda S, Ishihama A. Regulation of RNA polymerase sigma subunit synthesis in Escherichia coli: Intracellular levels of four species of sigma subunit under various growth conditions. J Bacteriol 1996; 178: 5447-5451.

20. Burton Z, Burgess RR, Lin J, Moore D, Holder S, Gross CA. The nucleotide sequence of the cloned rpoD gene for the RNA polymerase sigma subunit from E. coli K12. Nucleic Acids Res 1981; 9: 2889-2903.

21. Gitt MA, Wang L-F, Doi RH. A strong sequence homology exists between the major RNA polymerase sigma factors of Bacillus subtilis and Escherichia coli. J Biol Chem 1985; 260: 7178-7185.

22. Tomb J-F, White O, Kerlavage AR et al. The complete genome sequence of the gastric pathogen Helicobacter pylori. Nature 1997; 388: 539-547.

23. Benaïssa M, Babin P, Quellard N, Pezennec L, Cenatiempo Y, Fauchère JL. Changes in Helicobacter pylori ultrastructure and antigens during conversion from the bacillary to the coccoid form. Infect Immun 1996; 64: 2331-2335.

24. Kell DB, Kaprelyants AS, Weichart DH, Harwood CR, Barer MR. Viability and activity in readily culturable bacteria: a review and discussion of the practical issues. Antonie Van Leeuwenhoek 1998; 73: 169-187.

25. Donelli G, Matarrese P, Fiorentini C et al. The effect of oxygen on the growth and cell morphology of Helicobacter pylori. FEMS Microbiol Lett 1998; 168: 9-15.

26. Lyons JW, Siebenthal CD. On the binding of condensed phosphates by proteins. Biochim Biophys Acta 1966; 120: $174-176$.

27. Kusters JG, Gerrits MM, Van Strijp JAG, VandenbrouckeGrauls CMJE. Coccoid forms of Helicobacter pylori are the morphologic manifestation of cell death. Infect Immun 1997; 65: $3672-3679$ 